\title{
Percepção ambiental do corpo docente e discente da modalidade EJA de uma escola estadual no município de Pombal-PB
}

\section{Environmental perception of teachers and students of EJA (Young and Adults Educa- tion) of a public school in Pombal-PB}

\author{
Sanduel Oliveira de Andrade ${ }^{1}$, Arthur Victor Medeiros Francelino ${ }^{2}$, Diêgo Lima Crispim ${ }^{3}$, Eliana Pereira de Sousa $^{4}$, Adriana $^{2}$ \\ Gomes de Lima 5 .
}

\begin{abstract}
Resumo: A educação é um processo que abrange dimensões humanas, técnicas e político-social e seu desafio consiste em construir uma dinâmica articulada nos contextos políticos e sociais. Dentro deste contexto está a Educação Ambiental cujo intuito é explanar aos alunos a importância do meio ambiente que estamos inseridos e desenvolver práticas sustentáveis. Portanto, a presente pesquisa objetivou investigar o nível de percepção ambiental dos professores e alunos da modalidade EJA (Educação de jovens e adultos) da Escola Estadual de Ensino Médio Monsenhor Vicente Freitas, município de Pombal-PB e suas relações com o meio ambiente. O trabalho foi desenvolvido no período de julho a novembro de 2015 . Foram aplicados questionários com os professores e alunos que se enquadram na modalidade em estudo. Os alunos apresentaram boa noção em relação ao conceito de meio ambiente e dos seus elementos. Em virtude da grave crise hídrica vivida na região Nordeste brasileira, o tema de maior interesse observado, tanto por alunos quanto por professores foi o uso racional dos recursos hídricos. Os alunos creem que a disciplina de biologia favorece um ambiente mais propício para trabalhar a temática de educação ambiental, todavia se faz necessário que essa temática seja trabalhada de forma transversal nas demais disciplinas. Por parte dos professores, estes destacam a importância de incentivos financeiros para trabalhar com maior eficiência deste tema e fazer uso da privilegiada estrutura física da escola.
\end{abstract}

Palavras-chaves: Sustentabilidade, Educação de Jovens e Adultos, Temas transversais.

Abstract: Education is a process that includes human dimensions, technical and sociopolitical and your challenge is to build a dynamic articulated in political and social contexts, inside this context, the Environmental Education, whose aim is to explain to students the importance of the environment that we operate and develop sustainable practices. Therefore, the present study aimed to investigate the level of environmental perception of teachers and students of Young and Adults Education mode of Monsenhor Vicente Freitas School, municipality of Pombal-PB and its relationship with the environment. This study was developed in the period from July to November 2015. Questionnaires were applied to teachers and students who fall into the mode of study. The students have good sense of the concept of environment and its elements. Due to the severe water crisis experienced in the Brazilian Northeast, the topic of greatest interest observed, both by students and by teachers was the rational use of water resources. Students believe that biology discipline provides a more conducive environment to work the theme of environmental education. However, it is necessary that this issue be worked across the board in other disciplines. From teachers, they highlight the importance of financial incentives to work more efficiently this topic and make use of privileged physical structure of the school.

Key words: Sustainability, Youth and Adult Education, School.

\footnotetext{
*Autor para correspondência

Recebido para publicação em 24/01/2016; aprovado em 20/03/2016

${ }^{1}$ Engenheiro Agrônomo. Universidade Federal de Campina Grande (UFCG); Especialista em Geoprocessamento. Faculdades Integradas de Patos (FIP); Especialista em Educação Ambiental e Geografia do Semiárido. Instituto Federal do Rio Grande do Norte (IFRN). Mestrando em Sistemas Agroindustriais. Universidade Federal de Campina Grande (UFCG). E-mail: sanduelandrade@ hotmail.com

${ }^{2}$ Geólogo. Universidade Federal do Rio Grande do Norte (UFRN). Mestrado em Geodinâmica e Geofísica. Universidade Federal do Rio Grande do Norte (UFRN). E-mail: arthur.francelino@ifrn.edu.br

${ }^{3}$ Engenheiro Ambiental, Universidade Federal de Campina Grande - UFCG; Especialista em Educação Ambiental e Geografia do Semiárido. Instituto Federal do Rio Grande do Norte (IFRN). Mestre em Sistemas Agroindustriais, Universidade Federal de Campina Grande - UFCG. E-mail: diegolc_85@ hotmail.com.

${ }^{4}$ Licenciada em Ciências Biológicas. Universidade Federal de Campina Grande (UFCG). E-mail: elianapereirabio@gmail.com

5 Pedagoga, Universidade Estadual Vale do Acaraú - UVA; Especialista em LIBRAS. Instituto de Educação e Tecnologia (INET); E-mail: adri.gomes22@bol.com.br.
} 


\section{INTRODUÇÃO}

Gradativamente a concepção que a natureza existe para satisfazer o ser humano tem sido descartada, em virtude dos vários problemas ambientais causados pelo uso descontrolado de seus recursos. O homem possui forte dependência com a natureza, pois depende dela para sua sobrevivência, porém as necessidades do ser antrópico têm causado diversas alterações no meio ambiente, gerando impactos positivos ou negativos.

Para o ser humano, a adoção de certas mudanças em seus hábitos não é simples, requerem ações a logo prazo. Nesta perspectiva, a escola tem se tornado uma ferramenta capaz de realizar ações que despertem a conscientização e sensibilização ambiental, sendo trabalhadas as relações homem natureza, formando um cidadão crítico e criativo, com uma visão holística do mundo que os cerca, provocando mudanças em seu comportamento.

A educação é um processo que abrange dimensões humanas, técnicas e político-social e seu desafio consiste em construir uma dinâmica articulada nos contextos políticos e sociais. O professor age como colaborador na educação dos alunos, proporcionando a estes, uma mudança na forma de pensar, transformando suas vidas em processos constantes e contínuo de aprendizagem (CANDAU, 1999).

Para André (1995), a escola consiste em "terreno cultural caracterizado por vários graus de acomodação, contestação e resistência, uma pluralidade de linguagens e objetivos conflitantes".

Dentre desse contexto está inserida a Educação Ambiental, cujo objetivo é explanar aos alunos a importância do meio ambiente que estamos inseridos e desenvolver práticas que visem o uso sustentável dos recursos naturais, garantindo sua disponibilidade para as gerações vindouras. Dessa forma, o cuidado ao meio ambiente consiste em um princípio moral e ético, objeto de preocupação dos educadores (CHAWARTZMAN, 1999).

A Educação Ambiental, sob o viés crítico, poderá despertar no educando valores relacionados à questão ambiental, sendo além de uma abordagem comportamental. Também é importante para o processo de tomada de decisão no intuído de atingir um modelo de desenvolvimento sustentável, com mudanças de hábitos, tanto individuais quanto coletivos. Portanto, é necessário que cada educando desenvolva suas potencialidades e adote posturas construtivas, colaborando, assim, para a construção de uma sociedade justa e um ambiente saudável.

Para Waldman e Schneider (2000), o cidadão consciente não está apenas preocupado com o gasto da água, mas sim com a economia da energia elétrica e com a procura por alimentos e produtos mais saudáveis, a exemplo da agricultura orgânica, e com o descarte correto do lixo e reciclando o máximo possível.

Entretanto, a sociedade em geral ainda não tem atentado para questões simples, porém relevantes quando realizadas de forma coletiva, como a quantidade de água gasta para escovar os dentes, tomar banho, lavar a louça ou o carro. Empresas conceituadas, a exemplo da Colgate ${ }^{\circledR}$ (DEARO, 2015) e da CAGECE (Companhia de Águas e Esgotos do Estado do Ceará) (G1CE, 2015) têm realizados ações de conscientização, orientando a população como adotar práticas mais eficientes no uso racional dos recursos hídricos. Os recursos naturais, quando usados de maneira indiscriminada podem acarretar sérios problemas ambientais e escassez desses recursos.
A Educação Ambiental é de suma importância em todos os níveis dos processos educativos, inclusive na modalidade Educação de Jovens e Adultos (EJA). Por meio de ações de Educação Ambiental espera-se resgatar valores que abrangem o respeito pela diversidade cultural e biológica, indispensáveis para a conservação e para um convívio harmônico entre diferentes culturas e entre essas e a natureza.

No tocante a esta modalidade de ensino, essa acomodação, pluralidade de linguagem e objetivos conflitantes se tornam mais intensos, em virtude da heterogeneidade das turmas, composta de alunos de várias faixas etárias e visões diferentes sobre o mundo. Muitos estão voltando a estudar depois de um longo período fora de sala de aula, encontrando, assim, dificuldades de assimilação do conhecimento, obrigando o professor a adotar novas metodologias de ensino.

A EJA, no Brasil, está regida pelos Parâmetros Curriculares Nacionais (PCN). Essa modalidade de educação, tanto quanto as demais, abordam a Educação Ambiental como um tema transversal (FREITAS et al., 2009).

Historicamente, a modalidade EJA tem um caráter político de inclusão, por atender a uma clientela de alunos que foram privados da escolarização regular. No mais das vezes, o que traz essa parcela de alunos de volta à escola, após tempos de afastamento desse ambiente, é a inserção, ou uma melhor colocação no mercado de trabalho.

Neste contexto, a Escola Estadual de Ensino Médio Monsenhor Vicente Freitas é um estabelecimento oficial de ensino bem-conceituado e que tem gerado impactos positivos na sociedade local e regional, sendo importante conhecer o nível de percepção ambiental dos professores e alunos e de que forma estes assuntos estão sendo abordados.

Diante do exposto, o objetivo da presente pesquisa foi investigar o nível de percepção ambiental dos professores e alunos da modalidade EJA da E.E.E.M. Monsenhor Vicente Freitas, município de Pombal-PB e suas relações com o meio ambiente.

\section{MATERIAL E MÉTODOS}

O presente trabalho foi desenvolvido na Escola Estadual de Ensino Médio Monsenhor Vicente Freitas em Pombal, Estado da Paraíba (Figura 1) no período de julho e novembro de 2015. A Escola funciona nos períodos manhã, tarde e noite e oferece Ensino Médio Inovador, Profissionalizante, Regular Noturno e Educação de Jovens Adultos.

Figura 1 - Mapa de localização do município de Pombal-PB.

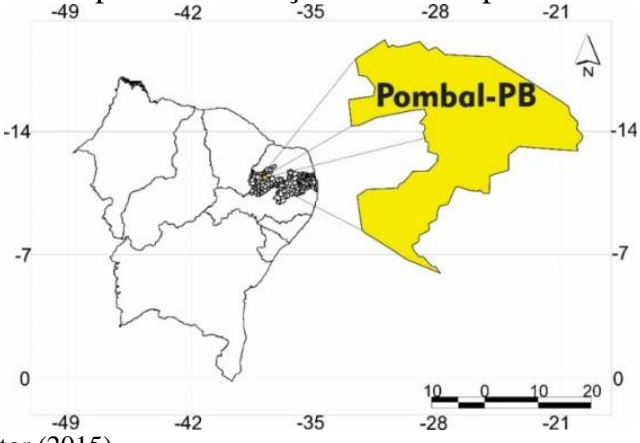

Fonte: Autor (2015)

A Escola apresenta uma estrutura física ampla e privilegiada e dispõe de vários ambientes adequados ao desenvolvimento de atividades administrativas e pedagógicas, com 21 
salas de aulas, auditório, biblioteca, sala de leitura, quadras de esporte, laboratórios diversos, dentre outros (Figura 2).

Figura 2 - Estrutura física da E.E.E.M. Monsenhor Vicente Freitas.

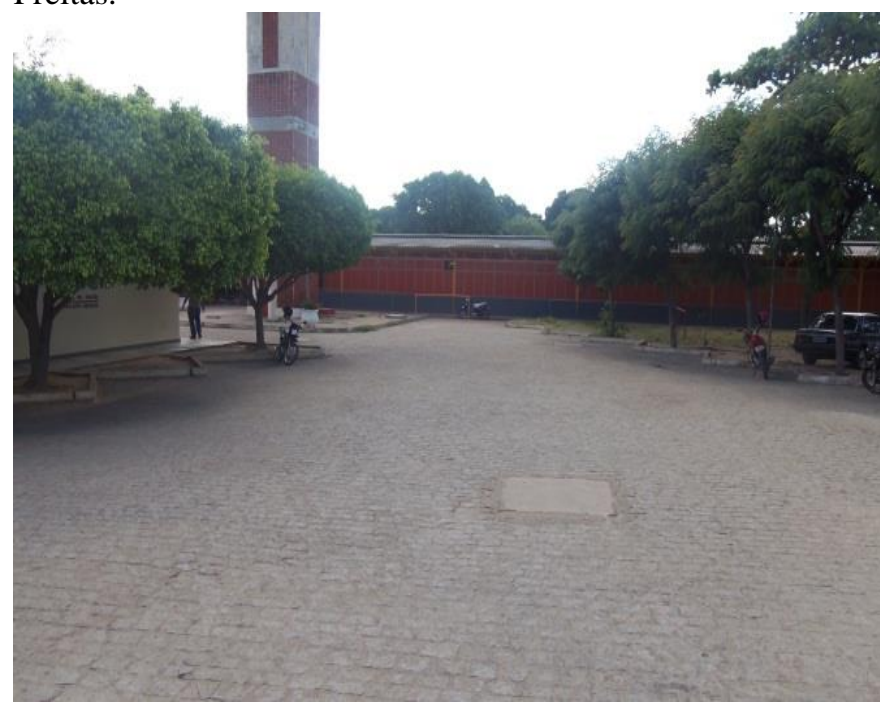

Fonte: Autor (2015).

No período diurno, a escola oferece ensino integral de qualidade a 700 alunos através do Programa Ensino Médio Inovador - ProEMI, além dos cursos profissionalizante de nível médio integrado, a exemplo do curso de Manutenção e Suporte em Informática.

Durante o turno noturno, a escola oferece o ensino médio na modalidade de Educação de Jovens e Adultos - EJA, atendendo a uma demanda de 80 estudantes. Estes alunos têm um diferencial, pois necessitam de uma atenção especial, visto que o alunado que a compõe possui necessidades particulares, devido terem permanecido durante um longo tempo excluído de um processo educativo formal. Tendo em vista que este alunado é composto de pessoas mais experientes e que passam o dia inteiro no trabalho para garantir seu sustento e da sua família.

Para avaliar o nível de percepção ambiental deste público alvo foram aplicados questionários a 23 alunos e 07 professores da referida escola, além de uma entrevista com corpo docente a respeito da abordagem da temática ambiental em sala de aula.

Também foram analisados os recursos didáticos que a escola oferece, como: livros, revistas, cartilhas, recursos audiovisuais, dentre outros, e como os professores tem trabalhado a temática ambiental com os alunos.

Para análise dos questionários será utilizado um padrão de contagem, aplicado um percentual e apresentados em forma de gráficos ou tabelas.

\section{RESULTADOS E DISCUSSÃO}

O alunado da modalidade Educação de Jovens e Adultos (EJA) da E.E.E.M. Monsenhor Vicente Freitas é composto por pessoas mais experientes e que trabalham durante o dia como guarda municipal, mecânico, bombeiro hidráulico, manicure, serralheiro, gari, dentre outros. A Lei das Diretrizes Básicas da Educação (Lei 9394/96), na seção V, dedicada a Educação de Jovens Adultos, salienta a necessidade da escola se adequar as condições de vida e trabalho do estudante, dando condições essenciais e incentivando a buscarem novos conhecimentos e, consequentemente, concluir a educação básica. Para Fischer e Godinho (2014), o vínculo com o trabalho contribui para a plena afirmação da EJA como direito do aluno no tocante ao acesso a educação.

Dos alunos entrevistados foi possível observar que grande parte possui uma faixa etária que varia de 18 a 20 anos, porém $22 \%$ possuíam idade acima de 30 anos, conforme descrita na Figura 3. Ferrari e Amaral (2005) enfatiza as dificuldades do docente em atender, em uma mesma sala, diferentes níveis de conhecimento e ritmos de aprendizagens. Com isso, o educador deve estar preparado para lidar com as mais diversas situações e aperfeiçoar seu desempenho em sala de aula. O convívio com pessoas de faixas etárias diferentes também pode ser um fator positivo, pois é possível intercambiar experiências, valores e condutas de cada geração.

Figura 3 - Faixa etária dos alunos entrevistados.

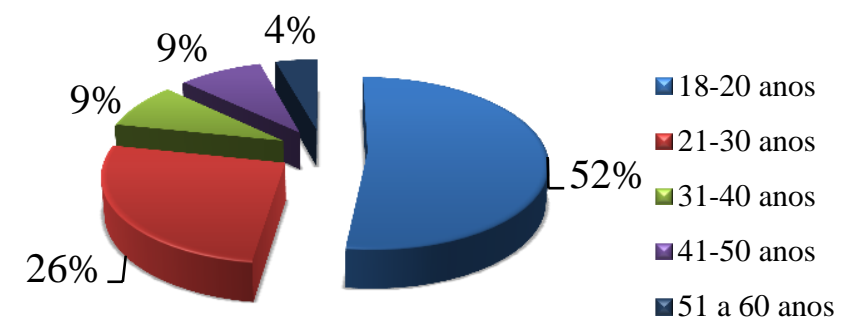

Fonte: Autor (2015)

No tocante ao conceito, $53 \%$ dos entrevistados creem que o meio ambiente consiste nos seres vivos e nos recursos, como ar, solo, água e alimentos, que a natureza oferece (Figura 4). A Lei 6938 de 31 de agosto de 1981 conceitua meio ambiente como "o conjunto de condições, leis, influências e interações de ordem física, química e biológica, que permite, abriga e rege a vida em todas as suas formas". Já Ceolato (2002) meio ambiente é a circunvizinhança em cuja área uma organização opera, abarcando o ar, a água, o solo, recursos naturais, a flora, a fauna, seres humanos e suas inter-relações. Diante desses conceitos foi possível afirmar que a maioria dos alunos entrevistados entende que a água, rios, ambientes urbanos e rurais, ar, fauna e flora fazem parte do meio ambiente.

Figura 4 - Conceito de meio ambiente dos entrevistados.

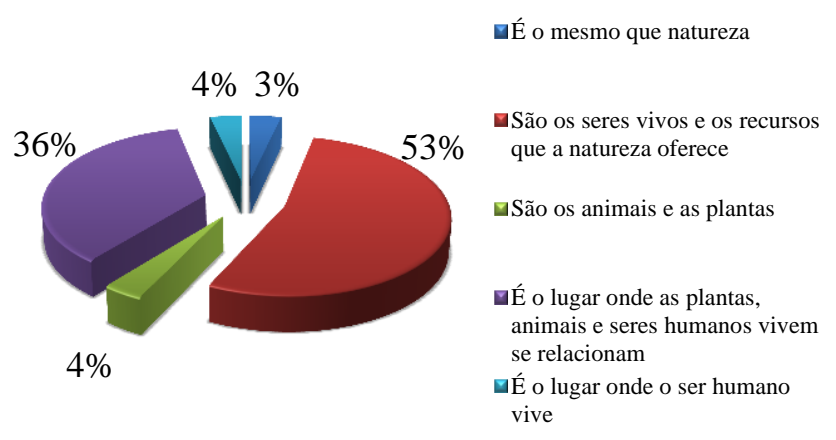

Fonte: Autor (2015).

Foi possível observar também que 70\% dos alunos entrevistados afirmaram se importar com meio ambiente (Figura 
6A). Os Parâmetros Curriculares Nacionais (PCNs) do Ministério da Educação (BRASIL, 1998) destacam a preocupação "em relacionar a educação com a vida do aluno - seu meio, sua comunidade - não é novidade. Ela vem crescendo especialmente desde a década de 60 no Brasil. Exemplo disso são atividades como os estudos do meio".

Contudo, quando indagados sobre quais atitudes tomariam para melhoria das condições do meio ambiente, esse número cai para $57 \%$ (Figura 5B). É preocupante o fato de que $43 \%$ ficariam omissos em realizar ações que venham a mitigar os danos ambientais ocorridos em sua comunidade. Silva \& Tomé (2014) destaca que é necessário a conscientização e mobilização da sociedade para a discussão e tomada de decisão em assuntos relacionados ao meio ambiente, visando à sustentabilidade, tanto no meio urbano quanto no rural. Entretanto $41 \%$ dos entrevistados tentariam estabelecer um diálogo com os moradores do bairro caso presenciassem alguém lançando lixo em local inapropriado, como terrenos baldios, rios, córregos, dentre outros (Figura 5C).

Figura 5 - A. Preocupação para com o meio ambiente. B. Atitudes de melhoria ao meio ambiente. C. Atitude ao presenciar o lançamento de lixo em local impróprio.
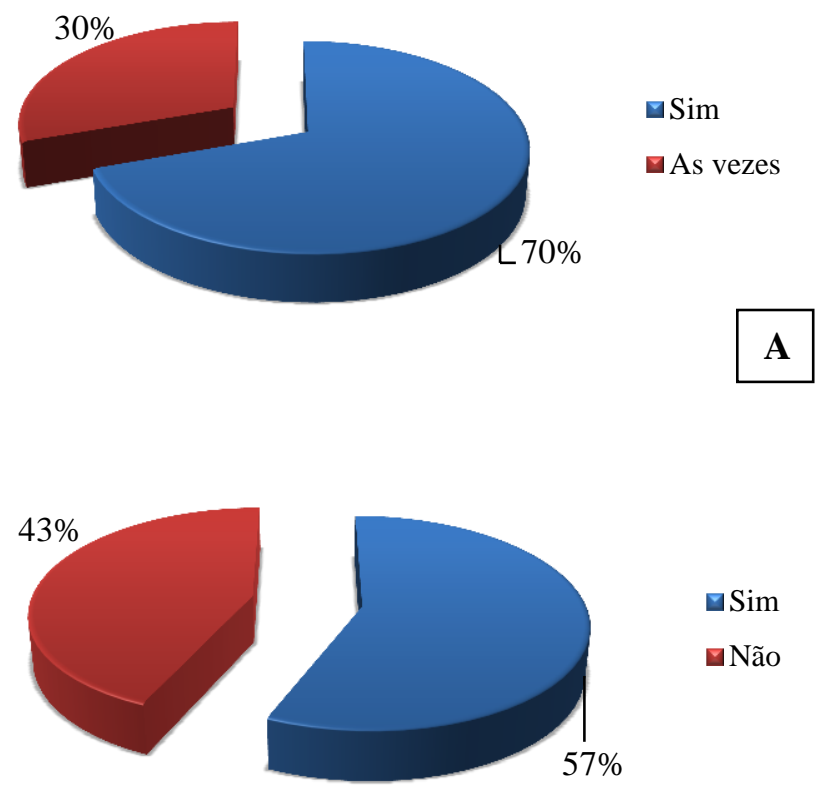

B

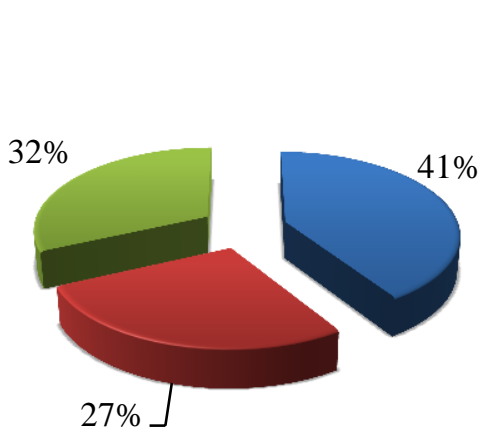

口Conversar com os moradores do bairro a não jogar lixo

Q Entrar em contato com a secretaria de obras (prefeitura) para remover o lixo

\Não importaria, pois não interfere na sua vida
Metade do alunado tem o conhecimento que o lixo coletado tem sido encaminhado para o lixão municipal, embora existam nas cidades algumas associações de catadores que recolhem uma parte dos resíduos gerados para a indústria de reciclagem (Figura 6).

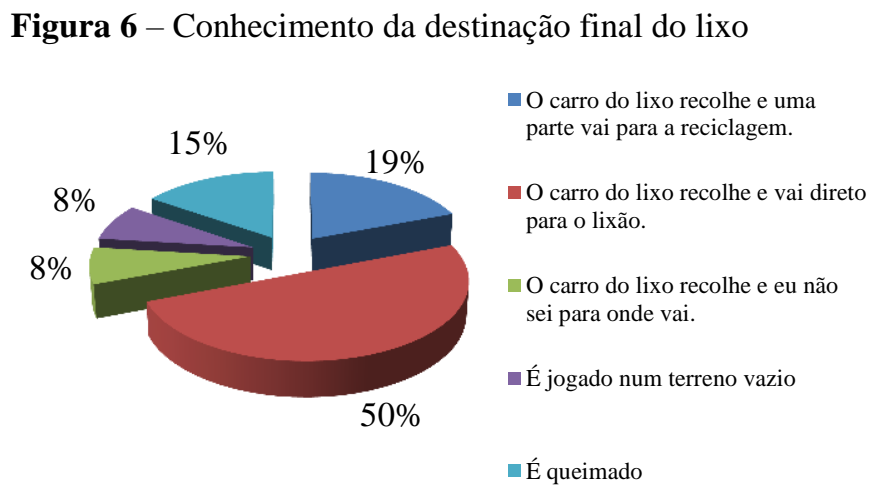

Fonte: Autor (2015).

Com a aprovação da Lei 12.305/2010 que trata da Política Nacional de Resíduos Sólidos, as cidades teriam um período de quatro anos para extinguir os lixões e criar os aterros sanitários, conforme estabelece a lei. Todavia, em agosto de 2014, boa parte das cidades não conseguiram cumprir este prazo, prorrogando por mais um ano (ROMANO, 2015). Todavia, em julho de 2015, o Senado Federal estipulou novos prazos para o fim dos lixões, que agora dependerá das peculiaridades de cada município, podendo variar de 2018 a 2021 (SALOMÃO, 2015).

Esta decisão se dá pelo fato do lixão ser uma área de disposição final sem nenhuma preparação do solo e sem nenhum sistema de tratamento dos efluentes líquidos gerados, a exemplo do chorume que possui alto potencial poluidor dos solos e dos mananciais hídricos em seu entorno. Os lixões também favorecem o desenvolvimento de moscas, mosquitos e ratazanas, que podem ser potenciais vetores de patogenicidades. Conforme Amorim et al, (2011) os aterros sanitários são os locais apropriados para a destinação final do lixo produzido, tendo como base critérios de engenharia e normas operacionais específicas que permitem sua confinação segura, visando mitigar os efeitos danosos ao meio ambiente.

A maioria do alunado (61\%) afirma saber diferenciar lixo de resíduo (Figura 7A). O termo lixo é mais comumente utilizado no vocabulário das escolas e comunidades. Para Amorim et al, (2011, p.04) "O lixo vira resíduo quando é reaproveitado". Entretanto, infelizmente $82 \%$ dos alunos entrevistados não possuem o hábito de realizar a separação do lixo para coleta seletiva (Figura 7B). Das várias formas de separação, a mais utilizada em residências é a segregação em lixo seco e em resíduos orgânicos.

Franchetti \& Marconato (2006) afirma que a reciclagem é o meio mais viável de reaproveitamento, principalmente de resíduos plásticos, transformando estes materiais em outros utilizados comercialmente, além de reduzir consideravelmente a quantidades de resíduos sólidos nos lixões e aterros sanitários.

Fonte: Autor (2015). 
Figura 7 - A. Conhecimento da diferença entre lixo e resíduo. B. Prática da coleta seletiva pelos alunos.
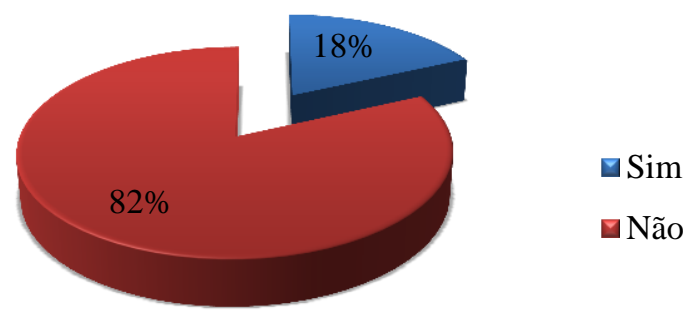

๑Não

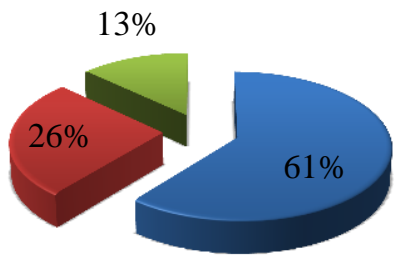

घSim
$\square$ Não
$\square$ Não há diferença

B

Fonte: Autor (2015).

Os resultados da pesquisa também mostraram que a maioria dos alunos possuem bons hábitos para economia de água, como escovar os dentes com a torneira fechada (78\%) (Figura 8A) e fechar o chuveiro durante o banho (65\%) (Figura 8B). Tais ações são de suma importância para economizar água, visto que a região de estudo tem sofrido consequências de uma grave estiagem que perdura há quatro anos. A redução no consumo de água também acarreará na redução dos efluentes gerados. Para Moraes e Jordão (2002) os efluentes domésticos se constituem na principal fonte de poluição de rios e lagos, visto que, grande parte dos municípios brasileiros não possui Estações de Tratamento de Esgotos (ETE), lançando os efluentes não tratados diretamente no meio ambiente. No caso do município de Pombal-PB, a Estação de Tratamento de Esgoto está sendo implantada. Até o momento, grande parte do efluente gerado é lançado no Rio Piancó sem seu devido tratamento.

Figura 8 - Ações práticas para economizar água.

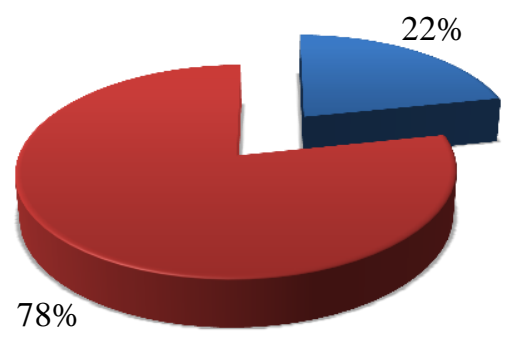

$\square \operatorname{Sim}$

๑Não

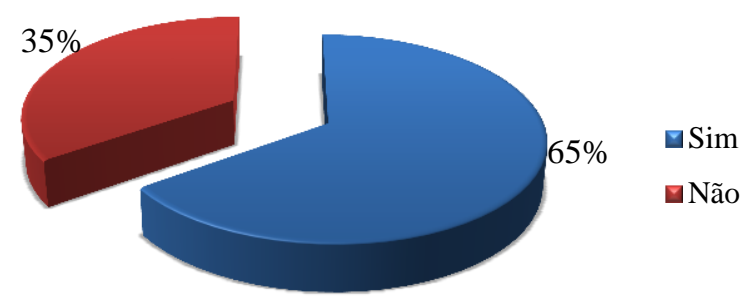

Fonte: Autor (2015).

Contudo, um número considerável de alunos afirma ter a prática de lavar calçadas e jardins corriqueiramente, tal prática utiliza-se grande quantidade de água (Figura 9). A prática do reuso consiste em um meio viável para reduzir o consumo de água. Um exemplo prático é a utilização da água oriunda da lavagem de roupas. Cunha et al. (2011) salienta que é possível a reutilização de águas para fins menos nobres como, descargas, lavagens de piso e outros.

Figura 9 - Frequência de lavagens de calçadas e jardins.
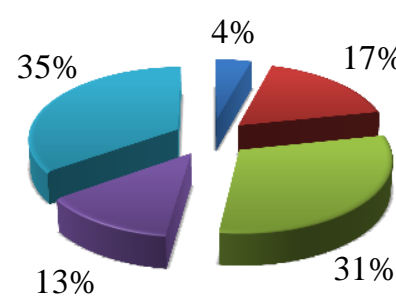

$\square$ Todos os dias

๑De uma a três vezes por semana

$\square$ De quinze em quinze

dias

- Mensal
Fonte: Autor (2015).

Quanto ao estudo da temática ambiental em sala de aula, $78 \%$ dos alunos afirmam ser importante a discussão do assunto (Figura 10A), principalmente do tema água, sugestão de $46 \%$ dos entrevistados (Figura 10B). Presume-se que a escolha por tal temática se dá pelo fato da região estar localizada no semiárido nordestino e que desde o ano de 2011 tem sofrido com uma forte estiagem, e muitos municípios encontramse em estado de calamidade (PRAZERES, 2015), onde 3,7 milhões de pessoas na região necessitam de abastecimento mediante carros-pipa cedidos pelo Governo Federal (GAMA; MADEIRO, 2015). Em Pombal-PB, até o presente momento, não houve redução significativa no abastecimento, em virtude do trecho perenizado do Rio Piancó que corta o município. Segundo Dionet (2009), a educação escolar consiste em um dos agentes fundamentais para a divulgação dos princípios da Educação Ambiental. 
Figura 10 - A. Opinião dos alunos a respeito da temática ambiental. B. Assuntos de interesses dos alunos a discutir.

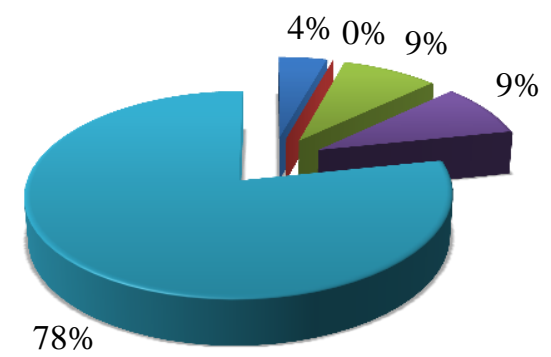

口Ruim

口Péssimo

घNão tenho

interesse

घÓtimo

Importante

A

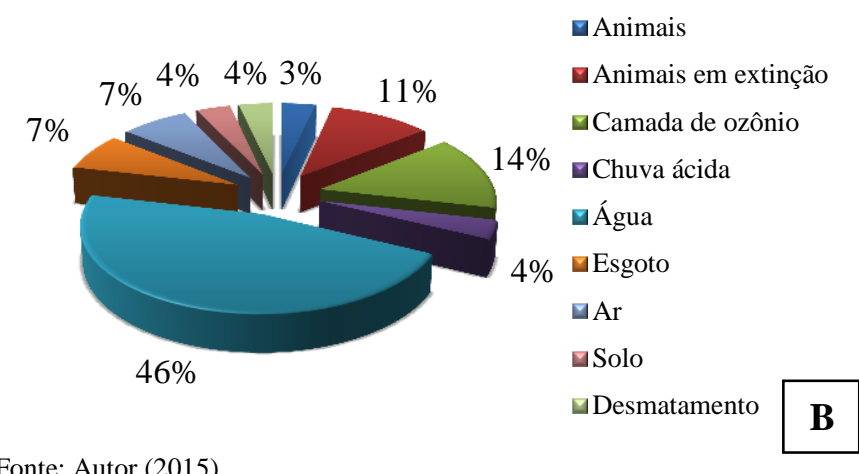

Fonte: Autor (2015).

No tocante à limpeza urbana, 61\% dos entrevistados consideram o município de Pombal - PB sujo (Figura 11). Para Fonseca et al. (2013), a ausência de sistema de gerenciamento de resíduos poderá acarretar inúmeros malefícios, como incidentes, acidentes, proliferação de doenças, dentre outros. Devido a isto, é mister o desenvolvimento de políticas que englobem iniciativas públicas e privadas, bem como a participação coletiva da comunidade a fim de reduzir a quantidade de lixo nas vias públicas, garantindo à população melhoria na qualidade de vida, em saúde pública e fortalecimento da relação do homem com o meio ambiente. Mucelin e Bellini (2008) salientam que o despejo inadequado de lixo poderá acarretar contaminação de corpos d'água, assoreamento, enchentes, proliferação de vetores transmissores de doenças, tais como cães, gatos, ratos, baratas, moscas, vermes, além da poluição visual, mau cheiro e contaminação do ambiente.

Figura 11 - Opinião pessoal dos alunos a respeito da limpeza urbana do município.

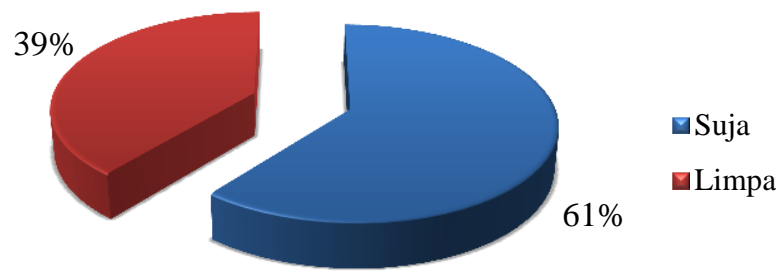

Fonte: Autor (2015).
A escola é o ambiente mais propício para desenvolvimentos de práticas de educação ambiental no intuito de conscientizar a comunidade sobre o destino correto do lixo gerado, evitando o lançamento destes no meio ambiente.

Os alunos entrevistados preferem abordar a temática ambiental mediante palestras (46\%), trabalhos e jogos educacionais $(29 \%)$ (Figura 12A). A disciplina mais propícia para trabalhar esta temática, de acordo com o alunado, foi a disciplina de Biologia (68\%) (Figura 12B).

Figura 12 - A. Forma de discussão das temáticas ambientais. B. Disciplina que deseja estuar a temática ambiental.

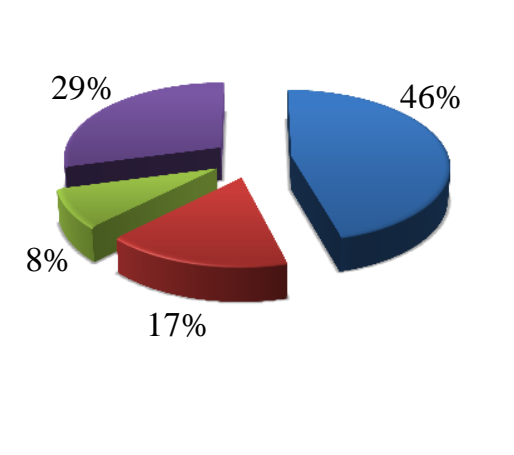

\section{$\nabla$ Palestras \\ ๑Vídeos \\ $\square$ Via Internet \\ - Trabalhos e jogos educacionais}

\section{A}

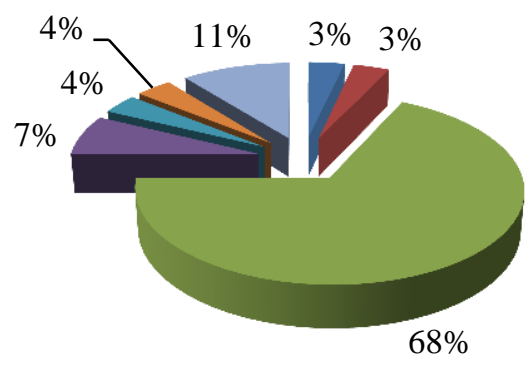

- Matemática

Arte

- Biologia

- Química

Sociologia

- História

Geografia
Fonte: Autor (2015).

Junqueira (2015) obteve êxito na utilização de jogos pedagógicos na abordagem da temática ambiental, destacando que seu dinamismo mostrou potencial para abordar o tema de forma transversal, o qual, por meio de relações interpessoais podem ser mais bem assimilados.

O perfil dos professores da modalidade EJA na unidade de ensino em estudo é composto por docentes do sexo feminino e a maioria possui o grau de Especialista. Para Machado (2012) existe a necessidade de se repensar os currículos dos cursos de licenciatura, para que a formação inicial trate mais especificamente a Educação de Jovens e adultos. O educador deve estar atento à realidade do seu alunado e saber lidar com certas situações tais como: alunos que chegam cansados e não conseguem manter-se acordados toda aula; como aplicar atividades extraclasses a um alunado que chega a trabalhar mais de oito horas diárias, incluindo fins de semana; como atender as diferenças geracionais, sendo as turmas multietárias e por fim, como avaliar a eficiência do processo ensino aprendizagem nos alunos?

Através dos questionários foi possível observar que, embora o professor já tenha certa experiência em sala de aula (Figura 13A), para muitos atuar na modalidade EJA está sendo uma experiência relativamente nova (Figura 13B). Machado (2012) destaca que há um número significativo de 
docentes atuando nesta modalidade nas redes públicas de ensino. Com isso, faz-se necessário elaborar estratégias de formação continuada, seja no nível de aperfeiçoamento, seja na perspectiva da pós-graduação latu sensu e stricto sensu.

O relatório do Encontro Nacional de Educação de Jovens e Adultos - ENEJA destaca a necessidade da garantia de investimentos do Poder Público na formação específica para o educador EJA, sendo este reconhecido como pesquisador de sua práxis pedagógica, sendo este o princípio orientador da formação na graduação e pós-graduação. Com isso, deve-se garantir o acesso dos educadores nas universidades de forma gratuita, além de criar mecanismos que viabilizem o processo de formação inicial e continuada (RESENDE, 2014).

Figura 13 - A. Tempo de atuação como professor. B. Tempo de atuação como professor da modalidade EJA.

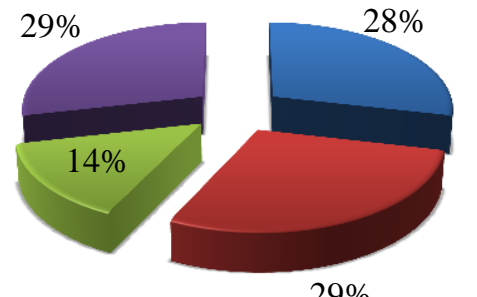

$29 \%$

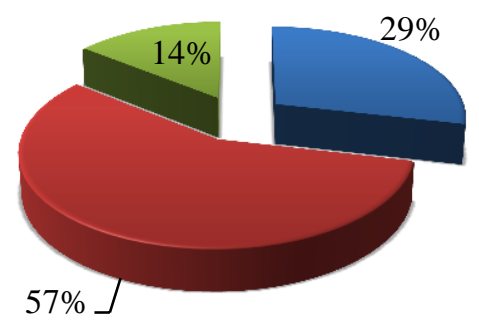

$\square$ Menos de 01 ano

๑01-05 anos

$\square 06-10$ anos
Fonte: Autor (2015).

A temática educação é abordada em quase todas as disciplinas (Figura 14), entretanto foi observado que ainda há a dificuldade de abordar esta temática nas disciplinas de cálculo, como matemática e física. Azcarate (1997) sugere correlacionar matemática e educação ambiental com energias alternativas, fontes e escassez de energia, gastos energéticos; crescimento populacional e demanda de alimentos; quantificação do consumo de água e formas de economia, dentre outros.

Groenwald e Filippsen (2003) desenvolveram algumas ações para abordar a temática ambiental em sala de aula, tais como o uso da função Polinomial de $1^{\circ}$ Grau a partir do Preço da Energia Elétrica em Função do Consumo e o uso de funções matemáticas relacionado crescimento populacional e demanda de alimentos.
Figura 14 - A. Professores que trabalham a temática ambiental em suas disciplinas. B. Incentivos para participar de projetos.
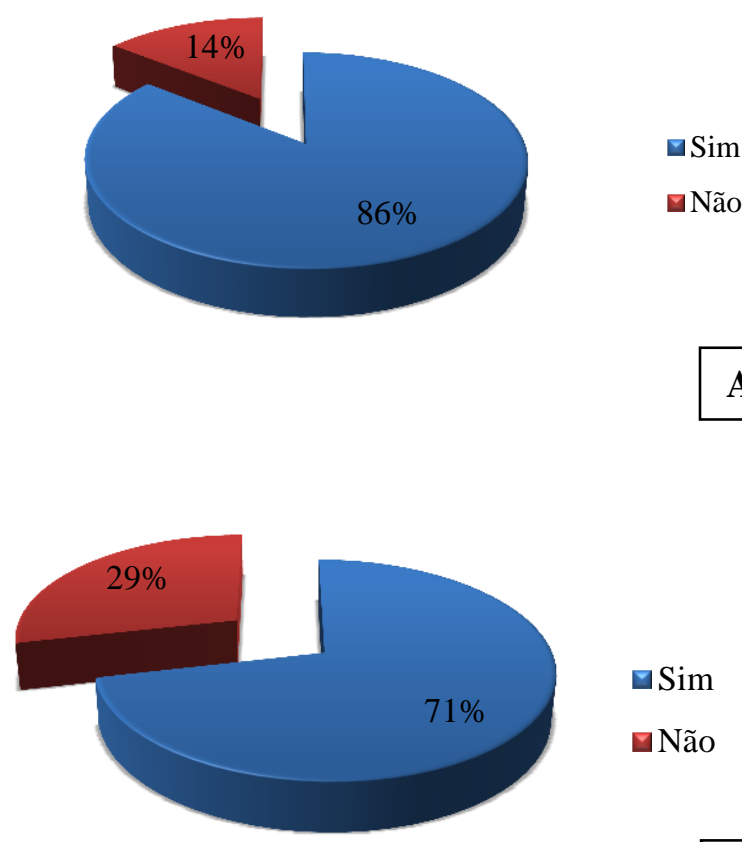

$\square \operatorname{Sim}$

๑Não

Fonte: Autor (2015).

Os professores também relataram algumas dificuldades em trabalhar esta temática em sala de aula. Entretanto, 71\% dos professores entrevistados relataram que recebem incentivos por parte da escola para desenvolverem projetos relacionados à temática em questão. Seguem as falas de alguns professores:

"Uma das dificuldades em trabalhar essa temática em sala de aula é talvez a falta de interação entre as disciplinas e os recursos financeiros e a falta de incentivo por parte da Secretaria Estadual de Educação"

"A maior dificuldade encontrada é contextualizar a temática com o programa de conteúdos de matemática";

"A falta de capacitação para os professores e maior comprometimento da comunidade escolar".

"A falta de material específico",

"Falta de material didático apropriado e recursos financeiros para proporcionar aulas de campo".

$\mathrm{Na}$ opinião dos professores entrevistados, a temática ambiental deve ser trabalhando com o auxílio de recursos tecnológicos, aulas de campo, aulas de laboratório, realização de palestras, seminários e pesquisas científicas. Outros professores destacam a importância de realização de uma ação com todos os professores e gestores escolares no intuito de conscientização da comunidade escolar, incluindo pais, ressaltando a importância da preservação do meio ambiente. Ações de contextualização também são importantes para trabalhar a temática de forma transversal, salienta outro docente. 
Indagados sobre a temática que os professores gostariam de abordar em um possível curso de formação continuada em Educação Ambiental, os mesmos destacaram: a preservação do meio ambiente; uso racional dos recursos hídricos, em virtude da grave crise hídrica enfrentada na região, conforme destacada anteriormente; sustentabilidade, com práticas inovadoras de economia de água e energia, como também a redução do uso de embalagens plásticas.

Por fim, os professores destacam as potencialidades da escola em abordar a temática ambiental na comunidade escolar, como recursos humanos qualificados, que possuem capacidade técnica e pedagógica para desenvolver ações com maestria; incentivo da escola, mesmo com recursos financeiros limitados; estrutura física e espaço livre privilegiado.

\section{CONCLUSÕES}

Diante do exposto, as novas perspectivas educacionais na abordagem da temática ambiental, permitem propiciar situações de aprendizagem focadas em aliar o conhecimento teórico ao prático, dando oportunidade aos alunos de compreender, conhecer e identificar os problemas ambientais locais, favorecendo a mudança de certos hábitos que não danosos ao meio ou mitigando os impactos negativos ocasionados ao meio ambiente.

Foi possível observar que há necessidade de abordar o tema com maior ênfase no ambiente EJA. Para isso, é de suma importância à articulação entre professores, pesquisadores e gestores, no intuito de aperfeiçoar o processo ensino aprendizagem, elevando sua qualidade educacional e gerando cidadãos críticos, conhecedores de suas responsabilidades sociais para o meio ambiente ao seu redor.

\section{REFERÊNCIAS BIBLIOGRÁFICAS}

AMORIM, A. P. et al. Lixão municipal: abordagem de uma problemática ambiental na cidade do Rio Grande-RS. Ambiente \& Educação-Revista de Educação Ambiental, v. 15, n. 1, p. $159-178,2011$.

ANDRÉ, M. E. D. A. Etnografia da prática escolar. São Paulo: Papirus, 1995

AZCÁRATE, P. Que matemáticas necessitamos para compreender el mundo actual? Investigación em la Escuela. 1997, $32,77-86$.

BRASIL. Lei $\mathrm{n}^{\circ} 12.305$, de 2 de agosto de 2010. Disponível em: <http://www.planal-to.gov.br/ccivil_03/_ato20072010/2010/lei/112305.htm>. Acesso em: 08 out. 2015 .

BRASIL. Lei $n^{\circ}$ 6.938, de 31 de agosto de 1981. Disponível em: $<$ http://www.planal-

to.gov.br/ccivil_03/Leis/L6938.htm>. Acesso em: 07 out. 2015.

BRASIL. Lei no 9.394, de 20 de dezembro de 1996. Disponível em: <http://www.planalto.gov.br/ccivil_03/Leis/L9394.htm>. Acesso em: 08 out. 2015.

BRASIL. Lei $\mathrm{n}^{\circ}$ 9.795, de 27 de abril de 1999. Disponível em: <http://www.pla-nalto.gov.br/ccivil_03/leis/19795.htm>. Acesso em: 04 jun. 2015.
CANDAU, V. M. Rumo a uma nova didática. Editora vozes Ltda., 10ª edição, p.55, Rio de Janeiro, 1999.

CEOLATO, L. C. Norma ISO 14001. In: Educação ambiental para o desenvolvimento sustentável, v.5, Agir, percepção da gestão ambiental, Ed. Hammes, V.S., Embrapa Informação Tecnológica, Brasília - DF, p.23-25, 2002.

CHAWARTZMAN, S. Consciência ambiental e desenvolvimento sustentável. 1999. Disponível em: <http://www.schwartzman.org.br/simon/ambiente.htm>.

Acesso em: 04 jun. 2015.

CUNHA, A. H. N.; OLIVEIRA, T. H. de; FERREIRA, R. B.; MILHARDES, A. L. M.; SILVA, S. M. da C. e. O reuso de água no Brasil: a importância da reutilização de água no país. Enciclopédia Biosfera, Centro Científico Conhecer -Goiânia, vol.7, N.13; 2011.

CZAPSKI, S. A Implantação da Educação Ambiental no Brasil. Coordenação de Educação Ambiental do Ministério da Educação e do Desporto. 1 ed. Brasília - DF, 1998.

DEARO, G. Colgate choca em nova campanha contra desperdício de água. Revista Exame, 25/06/2015. Disponível em: $<$ http://exame.abril.com.br/marketing/noticias/colgate-chocaem-nova-campanha-contra-desperdicio-de-agua>. Acesso em: 12 dez. 2015.

DIDONET, V. Educação infantil para uma sociedade sustentável. Revista Pátio - Educação Infantil. São Paulo, Ano VI n ${ }^{\circ}$ 18, Nov 2008 / Fev 2009.

FERNANDES, R. S., PELISSARI, V. B. Como os jovens percebem as questões ambientais. Revista Aprender, Ed. 13, Ano 3, Julho/Agosto 2003.

FERRARI, S. C.; AMARAL, Suely. O aluno de EJA: jovem ou adolescente?. Comissão Editorial, p. 7, 2005.

FISCHER, M. C. B.; GODINHO, A. C. F. Work, Education and Human Emancipation Humana: Affirming Youth and Adult Education as a right. Education Policy Analysis Archives, [S.1.], v. 22, p. 65, jun. 2014. ISSN 1068-2341.

FONSECA, M. D. et al. Os riscos relacionados ao ambiente e à atividade de coleta de resíduos sólidos urbanos. Revista Verde de Agroecologia e Desenvolvimento Sustentável, v. 8, n. 5, p. 96-100, 2014.

FRANCHETTI, S. M. M.; MARCONATO, J. C. Polímeros biodegradáveis-uma solução parcial para diminuir a quantidade dos resíduos plásticos. Química Nova, v. 29, n. 4, p. 811, 2006.

FREITAS, A. C. S.; SANTOS; J. E. O.; BARRETO, L. V. Educação ambiental no ensino de jovens e adultos. Centro científico conhecer - enciclopédia biosfera, v. 5, n. 8, 2009, p.1-11

G1CE. Cagece lança campanha contra desperdício de água no Ceará. Disponível em: <http://g1.globo.com/ceara/noticia/2015/07/cagece-lancacampanha-contra-desperdicio-de-agua-no-ceara.html $>$. Acesso em: 12 dez. 2015.

GAMA, A.; MADEIRO, C. Estiagem seca reservatórios do NE, e carros-pipa abastecem 3,7 mi. 2015. Disponível em: $<$ http://noticias.uol.com.br/cotidiano/ultimas-

noticias/2015/09/12/estiagem-seca-reservatorios-do-nordeste- 
e-carros-pipa-abastecem-37-mi.htm>. Acesso em: 08 out. 2015.

GROENWALD, C. L. O.; FILIPPSEN, Rosane Maria Jardim. Educação matemática e educação ambiental: educando para o desenvolvimento sustentável. Atas do IV Encontro Nacional de Pesquisa em Educação em Ciências. Baurú, SP, 2003.

MACHADO, M. M. Formação de professores para EJA: uma perspectiva de mudança. Retratos da Escola, v. 2, n. 2/3, 2012.

MARQUES, J. G. W. Etnoecologia, educação ambiental e superação da pobreza em áreas de manguezais. In: Encontro nacional de educação ambiental em áreas de manguezais, 1, 1993, Maragogipe. Anais... Maragogipe: UFBA, 1993, p. 2935 .

MORAES, D. S. de L.; JORDÃO, B. Q. Degradação de recursos hídricos e seus efeitos sobre a saúde humana. Revista Saúde Pública, v. 36, n.3, p. 370- 373, 2002.

MOURA, Dante Henrique. EJA: formação técnica integrada ao ensino médio. Revista Retratos da Escola, v. 2, n. 2-3, Brasília, 2006, p. 161-174.

MUCELIN, C. A.; BELLINI, M. Lixo e impactos ambientais perceptíveis no ecossistema urbano. Sociedade \& natureza, v. 20, n. 1, p. 111-124, 2008.

PRAZERES, L. Estiagem leva 16,8\% dos municípios brasileiros a decretar desastre. 2015. Disponível em: <http://noticias.uol.com.br/cotidiano/ultimas- noticias/2015/02/11/estiagem-leva-168-dos-municipiosbrasileiros-a-decretar-desastre.htm>. Acesso em: 08 out. 2015.

REZENDE, C. G. F. A formação de professores e a prática docente em geografia no contexto da educação de jovens e adultos mediados pela cartografia. Anekumene, v. 1, n. 5, p. 112-132, 2014

ROMANO, R. T. O problema do fim dos lixões. Revista Jus Navigandi, Teresina, ano 20, n. 4423, 11 ago. 2015. Disponível em: <http://jus.com.br/artigos/41597>. Acesso em: 08 out. 2015.

SÁ, Á. K. G. e.; PEREIRA, C. de A.; MOURA, R. C. G. Relação entre a teoria e a prática da Educação Ambiental na EJA do SESC - Petrolina/PE. Revista de Educação, Ciências e Matemática, v.2 n.1 jan/abr. Duque de Caxias, 2012.

SALOMÃO, L. Senado aprova prorrogação do prazo para extinção de lixões. 2015. Disponível em: <http://g1.globo.com/politica/noticia/2015/07/senado-aprovaprorrogar-por-2-anos-extincao-de-lixoes.html>. Acesso em: 8 out. 2015.

SILVA, T. B. M. da; TOMÉ, C. L. O discurso pedagógico e o conceito de sustentabilidade no discurso do professor e do aluno da Educação de Jovens e Adultos. Eventos Pedagógicos, v. 5, n. 2, p. 321-329, 2014.

WALDMAN, M.; SCHNEIDER, D.M. Guia Ecológico Doméstico. São Paulo: Contexto, 2000. 